\title{
KALIBRASI TLD-100 DI UDARA MENGGUNAKAN RADIASI SINAR-X PADA RENTANG RADIATION QUALITIES IN RADIODIAGNOSTIC (RQR)
}

\author{
Nisaul Chaira Yeni ${ }^{1, *}$, Dian Milvita ${ }^{1}$, Heru Prasetio ${ }^{2}$ \\ ${ }^{1}$ Jurusan Fisika FMIPA Universitas Andalas \\ ${ }^{2}$ PTKMR BATAN Jalan Lebak Bulus Raya No. 49, Jakarta Selatan \\ *Korespondensi ke: nisaulchaira14@gmail.com
}

( Diterima:09 Juli 2019; Direvisi: 25 Juli 2019; Diterbitkan: 01 September 2019)

\begin{abstract}
ABSTRAK
Telah dilakukan kalibrasi TLD-100 di udara menggunakan radiasi sinar-X pada rentang Radiation Qualities in Radiodiagnostic (RQR). Kalibrasi dilakukan untuk mengetahui koefisien kalibrasi TLD di udara, faktor koreksi kualitas radiasi dan pengaruh variasi dosis radiasi terhadap koefisien kalibrasi. Penelitian menggunakan pesawat sinar-X konvensional sebagai sumber radiasi, detektor TLD-100 sebagai detektor yang akan dikalibrasi dan detektor unfors-X2 sebagai detektor standar. Dosis radiasi yang digunakan yaitu $(0,2 ; 0,3 ; 0,5 ; 0,7)$ mGy dengan variasi tegangan $(50,60,70$, $80,90,100) \mathrm{kV}$. Hasil penelitian menunjukkan nilai koefisien kalibrasi TLD bergantung kepada kualitas radiasi sehingga TLD harus dikalibrasi pada setiap tegangan. Nilai faktor koreksi kualitas radiasi berada pada rentang $0,825 \pm 0,097$ sampai $1,039 \pm 0,084$ yang berarti kemampuan detektor merespon radiasi berbeda-beda seiring perubahan kualitas radiasi. Nilai koefisien kalibrasi meningkat seiring bertambahnya nilai dosis radiasi.
\end{abstract}

Kata kunci: koefisien kalibrasi, faktor koreksi, TLD

\begin{abstract}
Thermoluminisensi Dosemeter (TLD) calibration has been carried out in the air using Radiation Qualities in Radiodiagnostic (RQR) range. Calibration is to find TLD calibration coefficient in the air, the radiation quality correction factor and the effect of radiation dose variations on the calibration coefficient. The research used conventional X-ray as a radiation source, TLD-100 as a detector to be calibrated, the Unfors-X2 detector as a standard detector. The radiation dose used are $(0,2 ; 0,3 ; 0,5 ; 0,7) \mathrm{mGy}$ and the voltage used are $(50,60,70,80,90,100) \mathrm{kV}$. The results show that the value of the TLD calibration coefficient depends on the quality of the radiation, so the $T L D$ must be calibrated at each voltage. The value of the radiation quality correction factor is in the range $0.825 \pm 0.097$ to $1.039 \pm 0.084$ which means that the detector's ability to respond radiation is different with variance in radiation quality. The value of the calibration coefficient increases with increasing radiation dose values.

Keywords: calibration coefficient, correction factor, TLD
\end{abstract}




\section{PENDAHULUAN}

Seiring dengan kemajuan zaman, pemanfaatan sumber radiasi semakin pesat. Salah satu sumber radiasi yang digunakan adalah sinar-X. Beberapa peralatan medis yang menggunakan prinsip sinar-X yaitu pesawat sinar-X konvensional, CT-scan, mammografi, dental, dan fluoroskopi. Selain manfaatnya yang besar, penggunaan radiasi sinar-X dalam dunia medis juga memiliki potensi risiko yang cukup berbahaya bagi manusia dan lingkungan bila tidak memperhatikan prinsip-prinsip proteksi radiasi. Besarnya dosis radiasi yang diterima oleh pekerja radiasi maupun pasien dapat diketahui menggunakan detektor. Setiap detektor harus memiliki respon yang baik terhadap radiasi yang diterimanya. Keseragaman respon detektor terhadap perubahan energi dapat dilihat dengan nilai faktor koreksi. Hal tersebut diperlukan agar detektor menunjukkan nilai dosis radiasi yang sesuai dengan energi radiasi yang mengenainya.

Wijanarko (2010) melakukan penentuan respon detektor terhadap pesawat sinar-X menggunakan detektor Unfors, detektor jenis Farmer dan detektor TK 30 cc pada tegangan $50 \mathrm{kV}-100 \mathrm{kV}$. Nilai faktor koreksi detektor farmer bernilai kecil pada energi tinggi dan detektor kamar pengion dengan volume $30 \mathrm{cc}$ menghasilkan nilai faktor koreksi yang cenderung datar. Rahmi (2010) melakukan penelitian untuk mengevaluasi kualitas berkas radiasi RQR pesawat sinar-X berdasarkan protokol IAEA TRS No. 457 dan menentukan nilai faktor koreksi detektor Farmer 2571 dan detektor Termoluminisensi (TLD)-100 terhadap kualitas radiasi RQR. Radiation Qualities in Radiodiagnostic (RQR) adalah rentang kualitas radiasi pesawat sinar-X yang diaplikasikan pada pasien radiografi konvensional, fluoroskopi dan dental. RQR berada pada rentang RQR 2 sampai dengan RQR 10 (IAEA, 2007). Hasil studi menunjukkan nilai faktor koreksi detektor Farmer relatif konstan sedangkan detektor TLD-100 memiliki faktor koreksi yang tergantung dengan kualitas radiasi.

Pada penelitian ini dilakukan kalibrasi TLD-100 di udara untuk mengetahui besarnya koefisien kalibrasi TLD, faktor koreksi kualitas radiasi dan pengaruh variasi dosis radiasi terhadap koefisien kalibrasi. Penelitian bermanfaat bagi pekerja radiasi yang menggunakan TLD agar dapat mengetahui dosis radiasi yang diterimanya dengan akurat.

Dosimeter Termoluminesensi (TLD) merupakan salah satu jenis dosimeter pasif yang digunakan untuk pemantauan dosis radiasi, baik perorangan maupun lingkungan. Dosimeter TLD ini berbentuk zat padat, terbuat dari bahan kristal yang dapat menghasilkan efek tertentu ketika terkena paparan radiasi pengion. Radiasi pengion yang mengenai kristal termoluminesensi akan menyebabkan elektron-elektron yang berada di pita valensi berpindah ke pita konduksi. Elektron yang tereksitasi tersebut tidak dapat langsung kembali ke pita valensi karena terperangkap oleh pita energi unsur pendampingnya. Jika kristal dipanaskan maka elektron yang terperangkap akan mendapatkan cukup energi untuk kembali ke pita konduksi dan kemudian melakukan rekombinasi kembali ke pita valensi dengan memancarkan percikan cahaya. Bentuk perpindahan elektron dapat dilihat pada Gambar 1. 


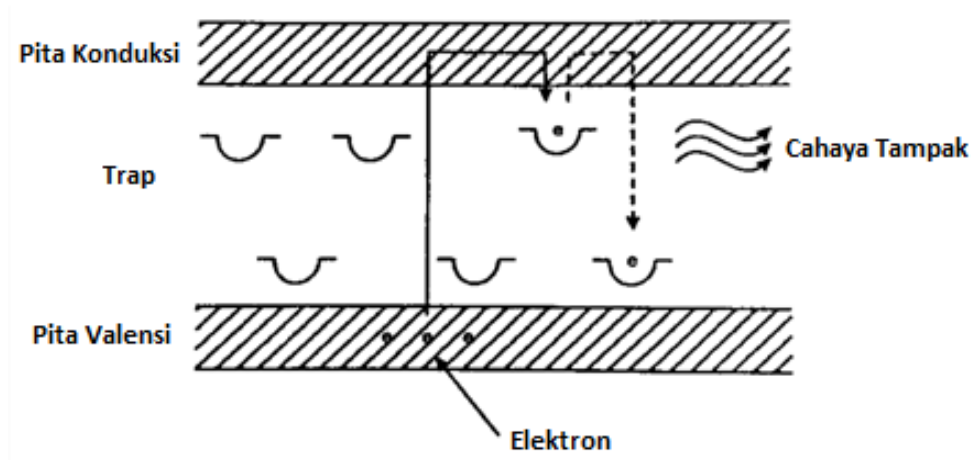

Gambar 1 Prinsip Dasar TLD (Dendy, P. P., dan Heaton, B., 1999)

Alat ukur proteksi radiasi harus dikalibrasi secara periodik. Hal ini dilakukan untuk menguji ketepatan nilai yang ditampilkan alat terhadap nilai sebenarnya. Perbedaan nilai antara yang ditampilkan dan yang sebenarnya harus dikoreksi dengan suatu parameter yang disebut sebagai faktor kalibrasi $\left(F_{k}\right)$. Dalam melakukan pengukuran, nilai yang ditampilkan alat harus dikalikan dengan faktor kalibrasinya. Faktor kalibrasi dapat dihitung dengan Persamaan 1.

$$
F_{k}=\frac{D_{s}}{D_{u}}
$$

dengan $D_{s}$ adalah nilai dosis radiasi alat ukur standar dan $D_{u}$ adalah nilai dosis radiasi alat ukur yang akan dikalibrasi.

Setiap detektor akan menghasilkan nilai yang berbeda ketika digunakan untuk besaran energi radiasi yang berbeda, sehingga diperlukan sebuah parameter yaitu faktor koreksi. Faktor koreksi berfungsi sebagai pengkoreksi nilai besaran radiasi yang terukur terhadap nilai besaran radiasi yang menjadi acuan. Faktor koreksi kualitas radiasi dapat ditentukan menggunakan Persamaan 2.

$$
K_{Q}=\frac{N_{K, Q}}{N_{K, Q_{o}}}
$$

dengan $K_{Q}$ adalah faktor koreksi kualitas radiasi, $N_{K, Q}$ adalah koefisien kalibrasi pada kualitas radiasi tertentu $(\mathrm{mGy} / \mathrm{nC})$ dan $N_{K, Q o}$ adalah koefisien kalibrasi pada kualitas radiasi referensi $(\mathrm{mGy} / \mathrm{nC})$.

\section{METODE PENELITIAN}

\subsection{Bahan dan Alat Penelitian}

Alat dan bahan yang digunakan yaitu pesawat sinar-X konvensional sebagai sumber radiasi sinar-X, TLD-100 sebagai detektor yang akan dikalibrasi, detektor Unfors-X2 sebagai detektor standar, TLD-reader untuk membaca hasil penyinaran TLD dan styrofoam sebagai pengganti medium udara

\subsection{Teknik Penelitian}

Pada penelitian ini dilakukan kalibrasi TLD-100 dengan melakukan penyinaran TLD di udara. Langkah-langkah penelitian dapat dilihat pada Gambar 2. 


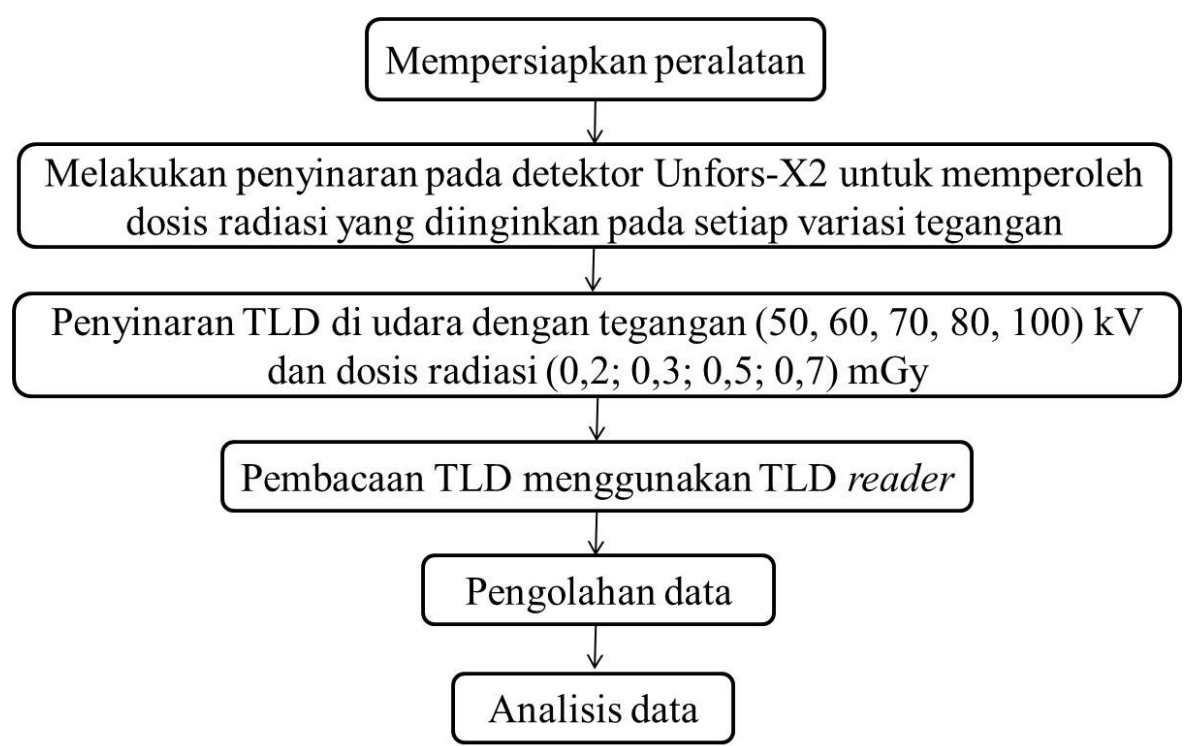

Gambar 2 Langkah-langkah penelitian.

Peralatan disiapkan dengan meletakkan detektor Unfors-X2 berada pada jarak $100 \mathrm{~cm}$ dari fokus tabung sinar-X dengan luas lapangan $25 \mathrm{~cm} \times 25 \mathrm{~cm}$. Sebelum menyinari TLD-100, terlebih dahulu dilakukan penyinaran pada detektor Unfors-X2 untuk memeroleh dosis radiasi keluaran sinar-X yang diinginkan pada setiap variasi tegangan. Detektor Unfors-X2 juga dapat menampilkan waktu penyinaran. Setelah didapatkan waktu penyinaran, TLD-100 disinari dengan variabel waktu dan posisi yang sama dengan detektor Unfors-X2 pada setiap tegangan.

\subsubsection{Teknik Pengolahan Data}

Penyinaran TLD di udara dilakukan untuk menentukan koefisien kalibrasi TLD, faktor koreksi TLD, dan pengaruh variasi dosis radiasi terhadap koefisien kalibrasi TLD. Perhitungan nilai koefisien kalibrasi dapat dilakukan menggunakan persamaan 1. Setelah didapatkan koefisien kalibrasi TLD dibutuhkan Faktor Koreksi Kualitas radiasi $\left(K_{Q}\right)$ di udara untuk melihat keseragaman nilai koefisien kalibrasi. Faktor koreksi didapatkan menggunakan Persamaan 3.

\subsubsection{Teknik Analisis Data}

Analisis data pengukuran dosis radiasi di udara meliputi pengaruh tegangan terhadap koefisien kalibrasi, pengaruh tegangan terhadap faktor koreksi TLD, dan pengaruh variasi dosis terhadap koefisien kalibrasi.

\section{HASIL DAN DISKUSI}

Hasil penyinaran TLD di udara mendapatkan nilai koefisien kalibrasi TLD dan faktor koreksi kualitas radiasi yang ditunjukkan pada Tabel 1. 
Tabel 1. Koefisien Kalibrasi TLD dan Faktor Koreksi Kualitas Radiasi

\begin{tabular}{ccccccc}
\hline No. & $\begin{array}{c}\text { Tegangan } \\
\text { Tabung } \\
(\mathbf{k V})\end{array}$ & $\begin{array}{c}\text { Dosis } \\
\text { Unfors-X2 } \\
(\mathbf{m G y})\end{array}$ & $\begin{array}{c}\text { \% Error Dosis } \\
\text { Unfors-X2 } \\
(\boldsymbol{\%})\end{array}$ & $\begin{array}{c}\text { Bacaan } \\
\text { TLD Udara } \\
(\mathbf{n C})\end{array}$ & $\begin{array}{c}\text { Koefisien } \\
\text { Kalibrasi, } \mathbf{F}_{\mathbf{k}} \\
(\mathbf{m G y} / \mathbf{n C})\end{array}$ & $\begin{array}{c}\text { Faktor } \\
\text { Koreksi, } \mathbf{K}_{\boldsymbol{Q}}\end{array}$ \\
\hline 1. & 50 & 0,507 & 1,418 & $7,765 \pm 0,704$ & $0,066 \pm 0,006$ & $0,825 \pm 0,097$ \\
2. & 60 & 0,499 & 0,187 & $7,073 \pm 0,609$ & $0,071 \pm 0,006$ & $0,889 \pm 0,090$ \\
3. & 70 & 0,490 & 2,053 & $6,137 \pm 0,454$ & $0,080 \pm 0,006$ & 1,000 \\
4. & 80 & 0,502 & 0,467 & $7,419 \pm 0,253$ & $0,068 \pm 0,002$ & $0,849 \pm 0,064$ \\
5. & 90 & 0,485 & 2,920 & $5,867 \pm 0,334$ & $0,083 \pm 0,005$ & $1,039 \pm 0,084$ \\
6. & 100 & 0,520 & 4,070 & $6,444 \pm 0,236$ & $0,081 \pm 0,003$ & $1,013 \pm 0,083$ \\
\hline & & & & Nilai maksimal & $0,083 \pm 0,005$ & $1,039 \pm 0,084$ \\
& & & & Nilai minimal & $0,066 \pm 0,006$ & $0,825 \pm 0,097$ \\
\hline
\end{tabular}

\subsection{Koefisien Kalibrasi TLD}

Pada Tabel 1 ditunjukkan dosis radiasi yang terukur oleh detektor Unfors-X2 tidak tepat dengan dosis radiasi yang diinginkan yaitu $0,5 \mathrm{mGy}$. Akan tetapi dosis radiasi yang terukur oleh detektor Unfors-X2 dapat digunakan untuk menyinari TLD karena memiliki persentase error lebih kecil dari $5 \%$.

Setelah TLD disinari dengan sinar-X pada berbagai variasi tegangan, selanjutnya didapatkan koefisien kalibrasi TLD pada rentang 0,066 $\pm 0,006 \mathrm{mGy} / \mathrm{nC}$ hingga $0,083 \pm$ $0,005 \mathrm{mGy} / \mathrm{nC}$ dengan selisih $0,017 \mathrm{mGy} / \mathrm{nC}$ dari nilai maksimum ke nilai minimum. Selisih nilai koefisien kalibrasi yang kecil menunjukkan kemampuan TLD untuk mengukur dosis radiasi dengan tepat karena koefisien kalibrasi berfungsi sebagai faktor pengubah besaran pada TLD menjadi besaran yang diinginkan.

Hubungan tegangan tehadap koefisien kalibrasi dapat dilihat pada Gambar 3.

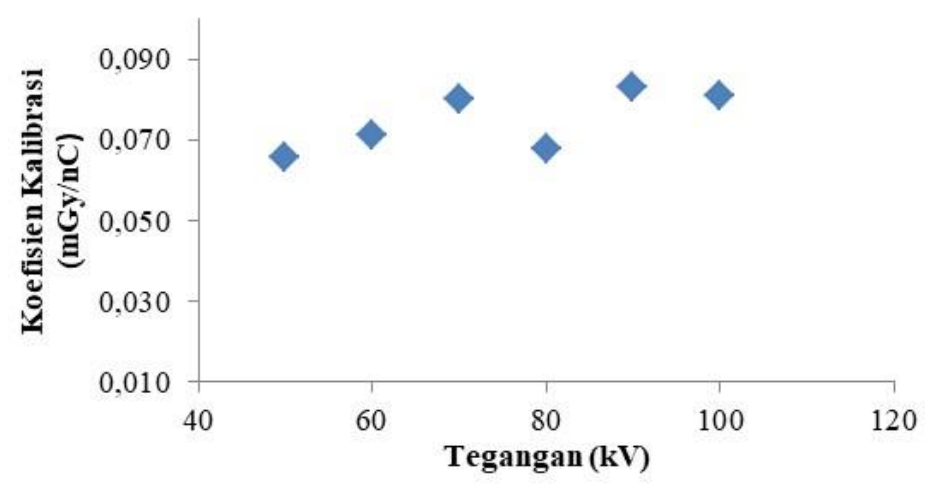

Gambar 3. Grafik hubungan tegangan terhadap koefisien kalibrasi

Hasil penelitian menunjukkan bahwa nilai koefisien kalibrasi meningkat pada tegangan $50 \mathrm{kV}$ sampai $70 \mathrm{kV}$ tetapi bernilai rendah pada tegangan $80 \mathrm{kV}$ dan kembali meningkat pada tegangan $90 \mathrm{kV}$. Penurunan nilai koefisien kalibrasi di tegangan $80 \mathrm{kV}$ terjadi karena adanya perbedaan spektrum pesawat sinar-X pada tegangan tersebut sehingga menghasilkan respon dosis radiasi yang berbeda pada detektor (Kardina, 2012). Oleh karena itu, TLD harus dikalibrasi pada setiap tegangan untuk mendapatkan nilai koefisien kalibrasi TLD. 


\subsection{Faktor Koreksi Kualitas Radiasi}

Koefisien kalibrasi yang didapatkan pada setiap tegangan memiliki nilai yang tidak sama, oleh karena itu dibutuhkan faktor koreksi kualitas radiasi. Faktor koreksi kualitas radiasi dibutuhkan untuk mengkoreksi nilai koefisien kalibrasi pada kualitas radiasi tertentu terhadap kualitas radiasi referensi. Kualitas radiasi yang menjadi referensi yaitu pada tegangan $70 \mathrm{kV}$ (IAEA, 2007). Hubungan tegangan terhadap faktor koreksi kualitas radiasi dapat dilihat pada Gambar 4.

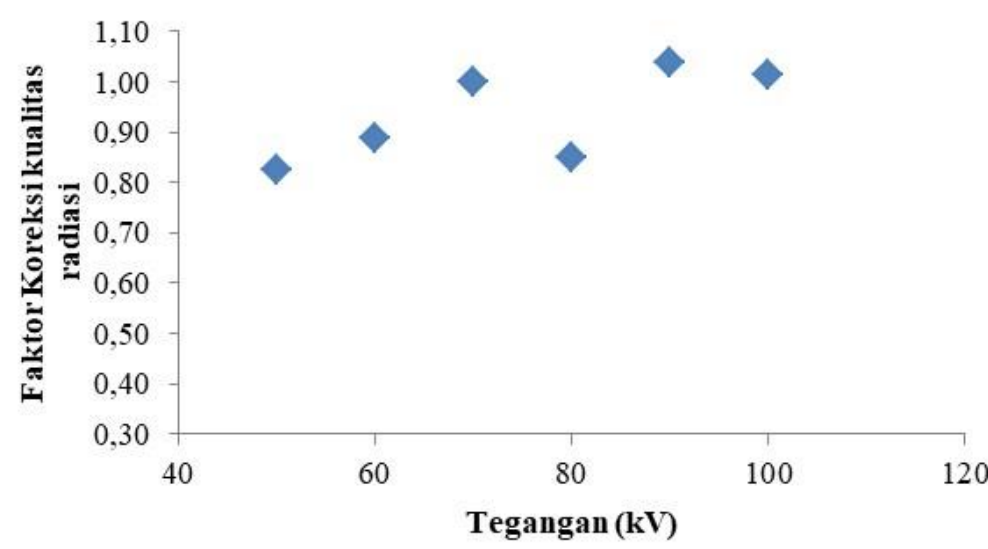

Gambar 4 Grafik hubungan tegangan terhadap faktor koreksi kualitas radiasi

Hasil penelitian menunjukkan bahwa faktor koreksi kualitas radiasi berfluktuasi seiring bertambahnya tegangan yang diberikan. Faktor koreksi mengalami penurunan pada tegangan $80 \mathrm{kV}$ karena koefisien kalibrasi pada tegangan tersebut lebih rendah daripada koefisien kalibrasi pada kualitas radiasi referensi. Faktor koreksi yang didapatkan berfluktuasi pada rentang 0,825 $\pm 0,097$ sampai 1,039 $\pm 0,084$ yang berarti kemampuan detektor merespon radiasi berbeda-beda seiring perubahan kualitas radiasi.

\subsection{Hubungan Variasi Dosis Radiasi terhadap Koefisien Kalibrasi}

Koefisien kalibrasi dipengaruhi oleh tegangan dan dosis radiasi. Hubungan dosis radiasi terhadap koefisien kalibrasi dapat dilihat pada Gambar 5.

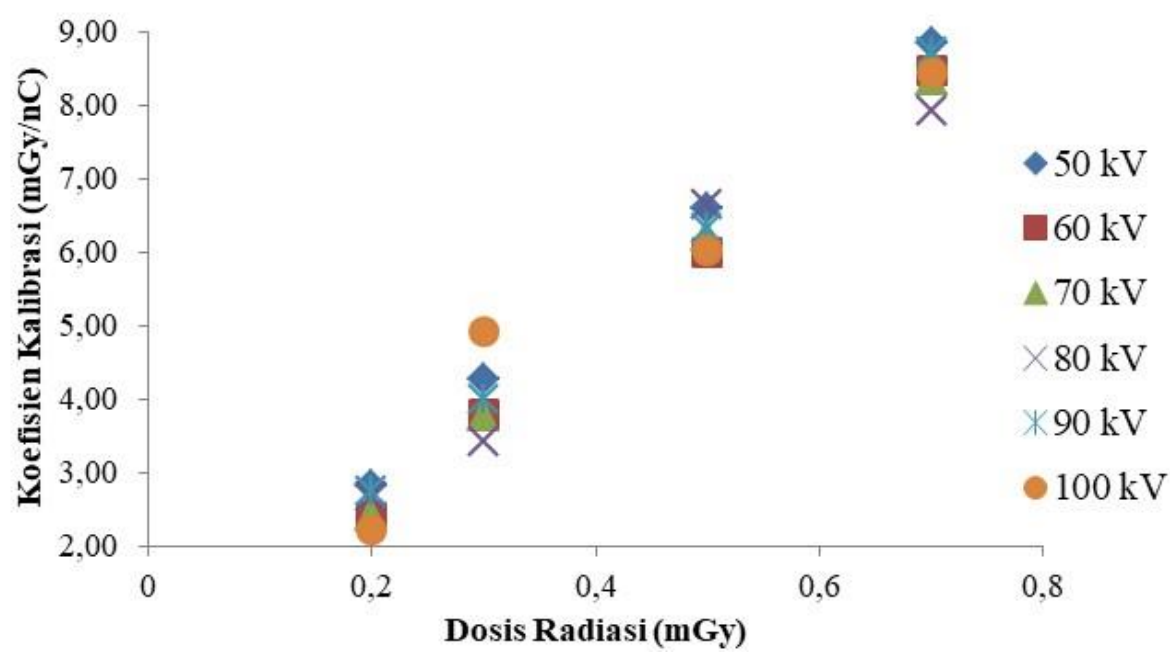

Gambar 5 Grafik hubungan variasi dosis radiasi terhadap koefisien kalibrasi 
Hasil penelitian menunjukkan bahwa dosis radiasi sebanding dengan koefisien kalibrasi pada setiap tegangan. Semakin besar dosis radiasi yang diberikan maka koefisien kalibrasi semakin besar. Hal tersebut terjadi karena dosis radiasi sebanding dengan koefisien kalibrasi berdasarkan relasi pada Persamaan 1. Selain itu, besarnya nilai koefisien kalibrasi hampir sama untuk setiap tegangan pada berbagai variasi dosis radiasi.

\section{KESIMPULAN}

Berdasarkan hasil penelitian yang dilakukan dapat disimpulkan bahwa pada pengukuran dosis radiasi di udara, perangkat TLD perlu dikalibrasi untuk setiap tegangan pesawat sinar-X. Faktor koreksi yang didapatkan berfluktuasi seiring perubahan kualitas radiasi. Selanjutnya diperoleh kesimpulan lain bahwa dosis radiasi sebanding dengan koefisien kalibrasi pada setiap tegangan.

\section{UCAPAN TERIMA KASIH}

Ucapan terima kasih kepada Instansi dan staff Pusat Teknologi Keselamatan dan Metrologi Radiasi (PTKMR) Badan Tenaga Nuklir Nasional (BATAN) Lebak Bulus Jakarta Selatan yang telah menyediakan sarana dan prasarana sehingga penelitian ini dapat terlaksana, serta semua pihak yang telah membantu kelancaran penelitian ini.

\section{DAFTAR PUSTAKA}

Akhadi, M. (2000). Dasar-dasar proteksi radiasi (hal. 60-64). Jakarta: PT. Rineka Cipta.

Beiser, A. (1981). Concepts of modern physics (hal 36-40). New York: McGraw-Hill Book Company.

Dendy, P. P., \& Heaton, B. (1999). Physics for diagnostic radiology (hal 135-137). London: IOP Publishing Ltd.

IAEA. (2007). Dosimetry in diagnostic radiology: An international code of practice, technical report series no. 457 (hal 330-332). Vienna: Author.

Kardina, A. (2012). Pengukuran spektrum pesawat sinar-X generator constant potential dan single phase menggunakan sistem spektroskopi (Skripsi). Universitas Indonesia, Depok, Indonesia.

Rahmi, A. (2010). Analisis faktor koreksi kQ,Qo detektor radiodiagnostik terhadap kualitas radiasi RQR menggunakan protokol IAEA TRS no. 457 (Skripsi). Universitas Indonesia, Depok, Indonesia.

Wijanarko, S. (2010). Respon detektor radiodiagnostik terhadap perubahan kualitas radiasi pesawat sinar-X pada rentang $R Q A$ berdasarkan technical report series no. 457 (Skripsi). Universitas Indonesia, Depok, Indonesia.

Perka BAPETEN No. 4 Tahun 2003. (2003). Proteksi dan keselamatan radiasi dalam pemanfaatan tenaga nuklir. Februari, 2019. https://jdih.bapeten.go.id 